\title{
Intraoperative Fiber-Optic Endoscopy for Ventricular Catheter Insertion
}

\author{
Philip V. Theodosopoulos, Aviva Abosch, Michael W. McDermott
}

\begin{abstract}
Objective: Ventricular catheter placement is a common neurosurgical procedure often resulting in inaccurate intraventricular positioning. We conducted a comparison of the accuracy of endoscopic and conventional ventricular catheter placement in adults. Methods: A retrospective analysis of data was performed on 37 consecutive patients undergoing ventriculo-peritoneal shunt (VPS) insertion with endoscopy and 40 randomly selected, unmatched patients undergoing VPS insertion without endoscopy, for the treatment of hydrocephalus of varied etiology. A grading system for catheter tip position was developed consisting of five intraventricular zones, V1-V5, and three intraparenchymal zones, A, B, C. Zones V1 for the frontal approaches and V1 or V2 for the occipital approaches were the optimal catheter tip locations. Postoperative scans of each patient were used to grade the accuracy of ventricular catheter placement. Results: Seventy-six percent of all endoscopic ventricular catheters were in zone V1 and 100\% were within zones V1-V3. No endoscopically inserted catheters were observed in zones V4, V5 or intraparenchymally. Thirty-eight percent of the conventionally placed catheters were in zone V1, 53\% in zones V1-3 and 15\% intraparenchymally. There was a statistically significant difference in the percentage of catheters in optimal location versus in any other location, favoring endoscopic guidance $(\mathrm{p}<0.001)$. Conclusion: We conclude that endoscopic ventricular catheter placement provides improved positioning accuracy than conventional techniques.
\end{abstract}

\begin{abstract}
RÉSUMÉ: Endoscopie peropératoire par fibres optiques pour l'insertion de cathéters ventriculaires. Objectif: La mise en place d'un cathéter ventriculaire est une procédure neurochirurgicale fréquente, souvent avec un positionnement intraventriculaire inexact. Nous avons comparé l'exactitude du positionnement ventriculaire de cathéters par endoscopie et par la méthode conventionnelle chez des adultes. Méthodes: Une analyse rétrospective des observations sur 37 patients consécutifs qui ont subi cette intervention par endoscopie et 40 patients sélectionnés au hasard, sans appariement, qui ont subi cette intervention sans endoscopie pour traiter une hydrocéphalie d'étiologie variée. Un système de classification de la position de la pointe du cathéter comprenant 5 zones intraventriculaires, V1-V5, et trois zones intraparenchymateuses A, B, C a été développé. Les zones V1 pour les approches frontales et $\mathrm{V} 1$ ou V2 pour les approches occipitales se sont avérées être les sites optimaux pour la pointe du cathéter. Les scans postopératoires de chaque patient ont été utilisés pour classifier l'exactitude du positionnement du cathéter. Résultats: Soixante-dix-sept pourcent de tous les cathéters placés sous endoscopie étaient dans la zone V1 et $100 \%$ étaient dans les zones V1-V3. Aucun des cathéters placés sous endoscopie n'était dans les zones V4, V5 ou dans le parenchyme. Trente-huit pourcent des cathéters mis en place par la méthode conventionnelle étaient dans la zone V1, 53\% dans les zones V1-V3 et 15\% dans le parenchyme. La différence entre le pourcentage des cathéters en position optimale et celui des cathéters en toute autre position était significative et en faveur du guidage endoscopique ( $\mathrm{p}<0.001)$. Conclusion: Nous concluons que la mise en place de cathéters par endoscopie ventriculaire améliore la précision du positionnement par rapport aux techniques conventionnelles.
\end{abstract}

Can. J. Neurol. Sci. 2001; 28: 56-60

The placement of ventricular catheters for external ventricular drainage or as one component of a ventriculoperitoneal shunt (VPS) is one of the most common neurosurgical procedures. Accurate positioning is crucial in the function of the catheter and in avoiding complications. ${ }^{1}$ Catheter tips located outside the ventricle or adjacent to choroid plexus may result in shunt malfunction and proximal obstruction is the leading cause of VPS malfunction. ${ }^{2-5}$ Pathologic examination of the contents of malfunctioning catheters often reveals pieces of choroid plexus filling the inside diameter of the catheter., ${ }^{4,6}$ Intraventricular hematoma and neuro-ophthalmic complications including optic

From the Department of Neurological Surgery, School of Medicine, University of California San Francisco, San Francisco, California USA.

ReCEIVED July 26, 2000. ACCEPTED IN FINAL FORM NOVEMBER 27, 2000

Reprint requests to: Michael W McDermott, c/o Department of Neurological Surgery, Moffitt Hospital M787, 505 Parnassus Ave, Box 0112, San Francisco, CA 94143 USA 
tract/optic nerve damage and dorsal pontine injury have been documented complications of improper ventricular catheter placement. ${ }^{7,8}$ In addition, the incidence of epilepsy after ventricular shunting procedures increases with multiple ventricular revisions, indicating that multiple areas of cortical damage may have clinically detrimental outcomes. ${ }^{9}$

Conventional ventricular catheter placement techniques have resulted in lower than expected accuracy of intraventricular positioning. In a study of the function of both frontal and occipital VPSs in children, Albright and colleagues found only $55 \%$ of the frontally placed catheters and $33 \%$ of the occipitally placed ones were in proper position. ${ }^{10}$ Functional survival of the shunts was twice as high in the correctly placed catheters than in the rest. Similarly, in a post hoc analysis of the pediatric cerebrospinal fluid (CSF) valve design trial data, Tuli et $\mathrm{al}^{1}$ showed a clear association between catheter tip environment and failure rate.

Recent technical advancements of neuroendoscopy have allowed its use in ventricular catheter placement resulting in improved accuracy of catheter placement. ${ }^{11-14}$ In a series of twenty-six children with hydrocephalus that underwent VPS insertion with the aid of neuroendoscopy and frameless stereotaxy, McCallum ${ }^{12}$ showed $92 \%$ proper ventricular catheter placement. Kellnar ${ }^{11}$ reported 17 cases in children where a VPS was inserted with the use of endoscopy and showed no shunt malfunction at 18 months of follow-up.

In order to determine whether endoscopic guidance improves

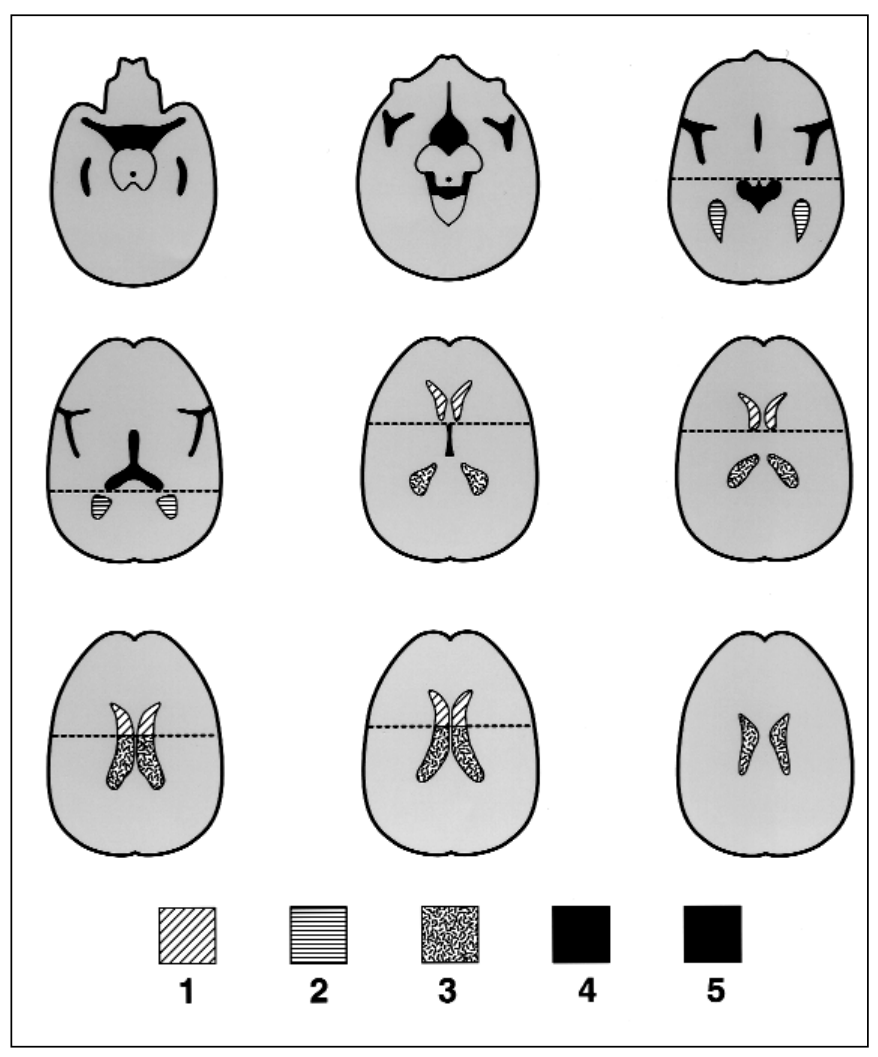

Figure 1: Grading of catheter tip position within the ventricular and subarachnoid spaces. ventricular catheter position we conducted a retrospective comparison of the accuracy of ventricular catheter placement with and without the use of neuroendoscopy, in adult patients with hydrocephalus undergoing VPS insertion or revision. The endoscopic procedures were performed by the authors of this study while the nonendoscopic catheter implantations were performed by other neurosurgical colleagues at our institution using conventional techniques.

\section{MeTHODS}

We reviewed the records of 37 consecutive patients with hydrocephalus of varied etiologies undergoing 42 procedures for a VPS insertion or revision with neuroendoscopy by the senior surgeon (MWM) at the University of California San Francisco. In addition, we reviewed the records of 40 randomly chosen patients who underwent a VPS insertion or revision for hydrocephalus without the use of endoscopy at the same institution during the same period of time. These procedures were performed by other neurosurgical colleagues at UCSF using conventional ventricular catheter insertion techniques. The diagnosis, age, side of shunt, the use of additional frameless stereotactic guidance, entry point location and complications were recorded.

For the neuroendoscopy aided cases, in every case the ventricular system was accessed initially with the Ellsberg cannula recording the depth at which the ventricle was entered as

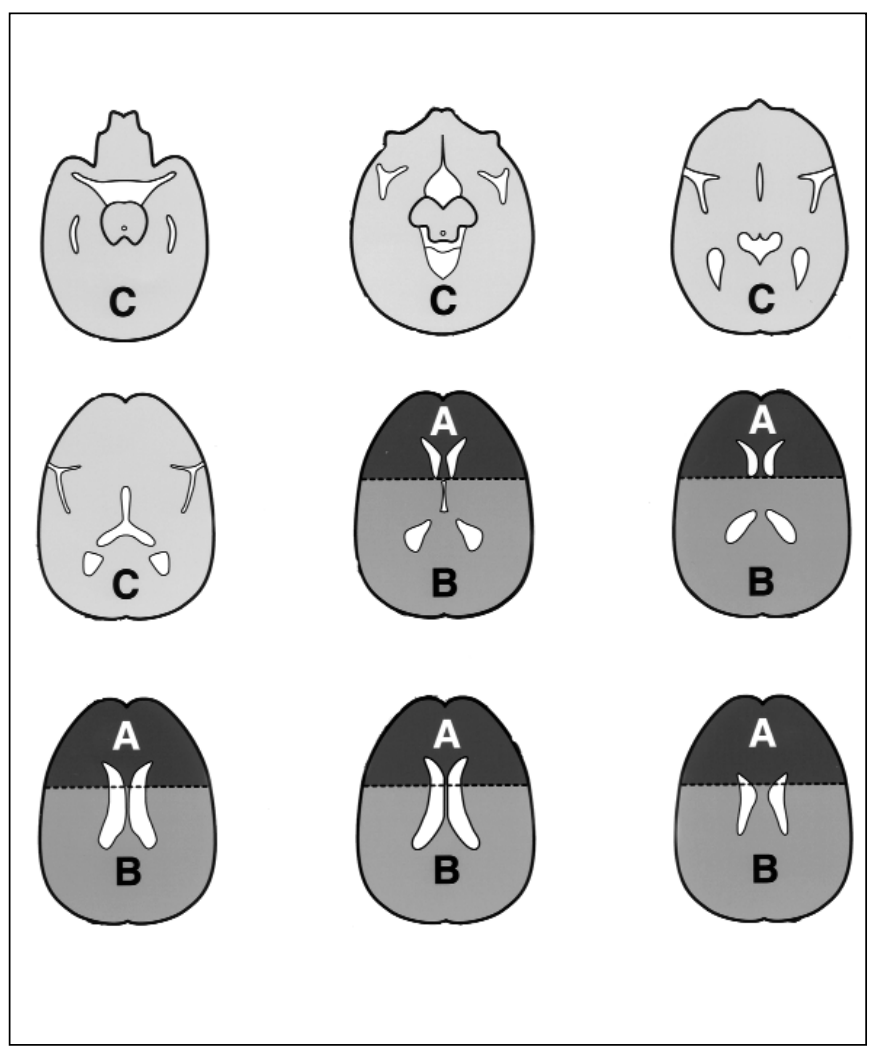

Figure 2: Grading of catheter tip position within the brain parenchyma. 
Table 1: Age, diagnosis and catheter entry location information for all patients.

\begin{tabular}{lcc}
\hline & Endoscopy-assisted & Conventional \\
Median Age (yrs) & 51 & 61 \\
Diagnosis: & & \\
$\quad$ Communication HCP & 28 & 32 \\
$\quad$ Noncommunicating HCP & 10 & 5 \\
Catheter entry: & & \\
$\quad$ Frontal & 32 & 38 \\
$\quad$ Occipital & 10 & 2 \\
Frameless stereotaxy use & 12 & 0 \\
\hline
\end{tabular}

measured at the brain surface. The trajectory used was based on anatomic landmarks and, in certain cases, confirmed with the use of frameless stereotaxy. The tip of the ventricular catheter was sliced $3 \mathrm{~mm}$ in the long axis of the catheter and care was taken to ensure that the $1.2 \mathrm{~mm}$ rigid NeuroNavigational endoscope (NeuroNavigational, Costa Mesa) was able to move freely inside the catheter and also to have its tip exit through the slit at the catheter tip. The ventricular catheter would then replace the Ellsberg cannula with the neuroendoscope serving as the stylette. Once the tip was in the ventricular system, the neuroendoscope would be advanced and the exact location within the ventricle would be determined. ${ }^{15,16}$ The catheter would be advanced over the endoscope with the goal of having the tip of the catheter at the foramen of Monroe. The endoscope would then be removed and the ventriculoperitoneal shunt would be completed. Frameless stereotaxy was used to access the ventricular system in all cases of benign intracranial hypertension.

For the nonendoscopic cases, anatomic landmarks were used and a trajectory perpendicular to the brain surface was followed. The ventricular catheter was used with a stylette for the initial accessing of the ventricle. Once adequate CSF flow was observed after the removal of the stylette, the catheter was cut at the appropriate length while still in position, and it was attached to the rest of VPS apparatus.

The first postoperative CT or MRI scan (when CT not available) was assessed by two independent, nonblinded examiners and the location of each catheter was recorded. The consensus location was used for the data analysis.

A grading scale for the location of the tip of the ventricular catheter on axial brain imaging was created. Five zones were established for locations within the ventricular system (V1-V5) and three zones for locations intraparenchymally $(\mathrm{A}, \mathrm{B}, \mathrm{C})$
Table 3: Ipsilateral vs. contralateral positioning of ventricular catheter tips.

\begin{tabular}{llc}
\hline Catheter Position & Ipsilateral & Contralateral \\
endoscopic & $36(86 \%)$ & $6(14 \%)$ \\
conventional & $34(85 \%)$ & $6(15 \%)$ \\
Total & $70(85 \%)$ & $12(15 \%)$ \\
\hline
\end{tabular}

Table 4: Comparison of optimal versus any other location for ventricular catheter tips.

\begin{tabular}{lcc}
\hline & V1 \& V2* & non V1, V2* \\
Endoscopic & 34 & 8 \\
Conventional & 17 & 23 \\
\hline
\end{tabular}

Fisher's exact test, two-tailed, $\mathrm{p}<0.001$

$* \mathrm{~V} 2$ for occipital approaches

(Figures 1 and 2). Zone V1 includes the area of the foramen of Monroe and, anterior to that, the frontal horns. This zone is the target area for a frontal or occipital ventricular catheter given the absence of choroid plexus. Zone V2 includes the occipital horns, a desirable location for catheters placed from an occipital approach, also because of the absence of choroid plexus. Zone $\mathrm{V} 3$ is defined by the bodies of the lateral ventricles posterior to a coronal plane passing through the foramen of Monroe. Zone $\mathrm{V} 4$ is the third ventricle and zone V5 is the peri-mesencephalic, suprachiasmatic and intrapeduncular cisterns, the aqueduct of Sylvius, and any other intraventricular location that is not included in the four other zones.

Zone A includes the frontal lobes anterior to the coronal plane passing through the foramen of Monroe and superior to the horizontal plane through the same. Zone B is the area posterior and superior to the same planes. Zone $\mathrm{C}$ is any location below the axial plane through the foramen of Monroe.

\section{RESUlts}

Forty-two consecutive VPS insertions were performed in 37 patients with the aid of endoscopy and 40 VPS insertions in 40 patients without endoscopy. There were no aborted neuroendoscopic placement attempts. Median age, diagnosis and ventricular catheter entry point were recorded (Table 1). In each case that neuroendoscopy was used, the foramen of Monroe and surrounding structures were observed with the neuroendoscope

Table 2: Location of catheter tip by ventricular and brain zone for all patients (percentage of all).

\begin{tabular}{llllllllll}
\hline Zone & V1 & V2 & V3 & V4 & V5 & A & B & C & Total \\
Endoscopic & 32 & 2 & 8 & 0 & 0 & 0 & 0 & 0 & 42 \\
& $(76 \%)$ & $(3 \%)$ & $(19 \%)$ & & & & & & \\
Conventional & 15 & 2 & 8 & 7 & 2 & 2 & 4 & 0 & 40 \\
& $(37.5 \%)$ & $(5 \%)$ & $(20 \%)$ & $(17.5 \%)$ & $(5 \%)$ & $(5 \%)$ & $(10 \%)$ & & \\
\hline
\end{tabular}


and the location of the catheter was determined intraoperatively.

There were a total of 32 frontal catheters in thirty patients and ten parietal-occipital catheters in seven patients inserted endoscopically. Seventy-six percent were in zone V1 and $100 \%$ were within zones V1, V2 and V3. (Table 2) Eighty-four percent of the frontally placed catheters and $50 \%$ of the occipitally placed ones were in zone V1. There were two occipital catheters $(5 \%)$ in zone V2 and eight catheters in zone V3 (19\%), out of which five were frontal and three were occipital. No catheters from either approach were placed in zones V4 or V5. No intraparenchymal catheter positioning was observed. Thirtyeight percent of the catheters inserted without endoscopy were in zone $\mathrm{V} 1,5 \%$ in zone $\mathrm{V} 2,20 \%$ in zone $\mathrm{V} 3,17.5 \%$ in zone V4 and $5 \%$ in zone V5. There were six intraparenchymal catheter tips, two in zone A and four in zone B (Table 2).

Fifteen percent of all the ventricular catheters crossed the septum pellucidum (Table 3). All but one of the catheter tips placed endoscopically that crossed the midline were located in zone V1 of the contralateral ventricle with the rest being slightly posterior to the foramen of Monroe in zone V3. Four of the nonendoscopically guided ones that crossed the midline were in zone V1, one was in zone V4 and one in zone B.

In $29 \%(12 / 42)$ of the endoscopic procedures frameless stereotaxy was used. Eighty-three percent (10/12) of the catheters placed with combined neuroendoscopic and frameless stereotactic guidance were in zone V1 with one catheter in zone $\mathrm{V} 2$ and one in zone V3.

When location within the optimal zone (V1 and V2 for occipital approaches) versus any other zone (V2 for frontal approaches, V3-5, A,B,C) is considered, a statistically significant difference favoring endoscopic placement is observed (Table 4).

There was one case of intra-operative cardiac arrhythmia associated with repeat subarachnoid hemorrhage in a 77-year-old woman with an inoperable, previously ruptured dolichoectatic basilar aneurysm. The patient had an unstable complicated ICU course and was allowed to expire after another postoperative repeat subarachnoid hemorrhage.

\section{Discussion}

The placement of ventricular catheters is a common neurosurgical procedure for the treatment of hydrocephalus and for intrathecal access. One of the most important complications in patients with ventricular catheters is catheter malfunction. In the case of VPS, the most common cause of malfunction is obstruction of the ventricular catheter from tissue in the vicinity of the catheter tip..$^{2-6,17}$

In an attempt to decrease the rate of catheter obstruction, several authors have argued for the placement of the catheter tip in the frontal horn, away from the choroid plexus. ${ }^{18,19}$ Yet, in a large retrospective study, Sainte-Rose et al failed to show an association of catheter tip location and long-term patency in children $^{3}$ and, in a more recent study by the same group, the best results for long term patency were achieved with catheter tips located in the occipital horn. ${ }^{20}$ It has not been until very recently that a clear answer was given to the importance of ventricular catheter tip position. A post hoc analysis of the data from the multicenter, randomized pediatric CSF shunt valve trial demonstrated that the catheter tip environment was the factor most predictive of shunt failure, with catheters surrounded by brain having the worst failure rate, followed by the ones with tips touching brain.

Despite the importance of catheter tip location for long-term patency, there is frequent inaccuracy of catheter positioning. In a study of 114 children with VPSs, Albright et $\mathrm{al}^{10}$ found that only $55 \%$ of the catheter tips were located in a good position, defined as in the ipsilateral frontal horn, anterior to the foramen of Monroe. Similarly, Pang and Grabb ${ }^{21}$ showed 53\% excellent ventricular catheter placement in 160 children with VPS. His grading of catheter position was based on stereotactic coordinates calculated on plain skull $\mathrm{x}$-ray films and corresponded roughly to location within the ipsilateral frontal horn, anterior to the foramen of Monroe.

Our results indicate an advantage for endoscopic placement of ventricular catheters. No catheters were positioned outside the ventricular system with the use of endoscopy, in contrast to $15 \%$ of the nonendoscopically guided ones. When locations within the ventricular system are considered, endoscopy assured placement of all the catheters in zones V1-V3, contained within the lateral ventricles, as opposed to $23 \%$ of the nonendoscopically inserted ones, with their tips surrounded by CSF outside the lateral ventricles.

Previous endoscopic studies have shown improved accuracy of ventricular catheter placement. ${ }^{11,12}$ These studies differed from ours in that they were conducted in children and that their patient enrollment was small. In young children, the anterior fontanelle is still open and this allows for the use of ultrasound for localizing the ventricular system. In addition, in one series a different endoscopic technique was used, utilizing a flexible endoscope to confirm the position of the catheter after it was positioned. ${ }^{12}$ The small diameter of the rigid fiber optic endoscope allows it to be placed through the ventricular catheter and thus minimizes passes of instruments through the brain parenchyma. Continuous endoscopic visualization during catheter placement ensures intraventricular location and exact positioning within the ventricle.

Despite endoscopic guidance, $20 \%$ of all catheters were placed in zone V3. Possible reasons for this inaccuracy include inappropriate advancement of the catheter after the removal of the endoscope and application of torque to the endoscope in the antero-posterior direction during ventriculoscopy, resulting in inaccurate estimation of catheter tip position once the endoscope was removed.

Our study suffers from all the disadvantages of a retrospective study. Although the cohort of nonendoscopic cases was randomly selected, they are not matched to the endoscopic ones and the bias from the lack of randomization might have influenced our findings. We believe, though, that none of the biases introduced in the patient selection process should have an effect on catheter tip positioning.

The lack of clinical follow-up and long-term VPS function information in either group is another limitation of our study. It was not our intention to evaluate long-term shunt patency. However, early failure from placement of a catheter into brain tissue can be avoided with direct visualization of intraventricular anatomy. While the cost of disposable endoscopes is several hundred dollars, this is minimal in comparison to early reoperation for repositioning of a ventricular catheter. 
The combination of neuroendoscopy and computer-aided image guidance in neurosurgery has been demonstrated by several studies. It allows for accurate burr hole placement and localization of the ideal trajectory for approaching the ventricular system. ${ }^{13,14}$ In our study, $86 \%$ of the patients who had combined endoscopic and frameless stereotactic guidance had ventricular catheters placed in zones V1 and V2. Our preliminary results demonstrate further improvement of ventricular access, especially in cases of slit ventricles, where conventional techniques have shown very high rates of proximal obstruction leading to VPS malfunction.

Positioning of the ventricular catheter in the contralateral frontal horn anterior to the foramen of Monroe, although not the preferred location, has no significant contraindications for catheter function. In fact, Steinbok ${ }^{22}$ showed significantly lower rate of ventricular asymmetry with catheters placed through the septum pellucidum compared to ones placed ipsilaterally. Thirteen percent of the catheters in our study were placed in the contralateral frontal horn. In all but one case, they were placed away from choroid plexus.

In our series, there is one patient that underwent five procedures. This patient had tuberous sclerosis with a subependymal giant cell astrocytoma and a CSF protein of 1,800. Despite appropriate ventricular catheter positioning in every case, the patient developed recurrent proximal malfunctions which we believe to be a result of the abnormal CSF contents.

\section{ConClusions}

Our results show that ventricular catheter positioning with the use of intra-operative fiber optic endoscopy is a very accurate technique. This is the first study in adult patients comparing endoscopic and conventional placement of VPSs. In addition, the use of the fiber optic $1.2 \mathrm{~mm}$ diameter endoscope offers the advantage of being able to utilize the endoscope as a stylette and therefore actively monitor the positioning of the catheter rather than simply confirm the final catheter position.

We conclude that ventricular catheter placement with the aid of rigid fiber optic endoscopy is a safe and efficient technique with improved accuracy over conventional methods. A prospective randomized trial is necessary to confirm our results and to compare the cost and long-term patency rate between endoscopic and nonendoscopic ventricular catheter placement.

\section{REFERENCES}

1. Tuli S, O'Hayon B, Drake J, Clarke M, Kestle J. Change in ventricular size and effect of ventricular catheter placement in pediatric patients with shunted hydrocephalus. Neurosurgery 1999;45: 1329-1335.
2. Kast J, Duong D, Nowzari F, Chadduck WM, Schiff SJ. Timerelated patterns of ventricular shunt failure. Childs Nerv Syst 1994;10: 524-528.

3. Sainte-Rose C, Piatt JH, Renier D, et al. Mechanical complications in shunts. Pediatr Neurosurg 1991;17: 2-9.

4. Sekhar LN, Moossy J, Guthkelch AN. Malfunctioning ventriculoperitoneal shunts. Clinical and pathological features. J Neurosurgery 1982;56: 411-416.

5. Serlo W, Fernell E, Heikkinen E, Anderson H, von Wendt L. Functions and complications of shunts in different etiologies of childhood hydrocephalus. Childs Nervous System 1990;6: 92-94.

6. Collins P, Hockley AD, Woollam DH. Surface ultrastructure of tissues occluding ventricular catheters. J Neurosurgery 1978;48: 609-613.

7. Kuwamura K, Kokunai T. Intraventricular hematoma secondary to a ventriculoperitoneal shunt. Neurosurgery 1982;10: 384-386.

8. Shults WT, Hamby S, Corbett JJ, et al. Neuro-ophthalmic complications of intracranial catheters [see comments]. Neurosurgery 1993;33: 135-138.

9. Dan NG, Wade MJ. The incidence of epilepsy after ventricular shunting procedures. J Neurosurgery 1986;65: 19-21.

10. Albright AL, Haines SJ, Taylor FH. Function of parietal and frontal shunts in childhood hydrocephalus. J Neurosurgery 1988;69: 883-886.

11. Kellnar S, Boehm R, Ring E. Ventriculoscopy-aided implantation of ventricular shunts in patients with hydrocephalus. J Pediatr Surg 1995;30: 1450-1451.

12. McCallum J. Combined frameless stereotaxy and neuroendoscopy in placement of intracranial shunt catheters. Pediatr Neurosurg 1997;26: 127-129.

13. McDermott MW, Ciricillo SF, Edwards MS. Neuroendoscopy. West J Med 1995;162: 261-262.

14. Rhoten RL, Luciano MG, Barnett GH. Computer-assisted endoscopy for neurosurgical procedures: technical note. Neurosurgery 1997;40: 632-637.

15. McDermott MW, Jacobs A. Application of the ISG Viewing Wand for Endoscopic Procedures. In: Tamki N, Ehara K, eds. Computer-Assisted Neurosurgery. Tokyo: Springer-Verlag, 1997: 59-68.

16. Walker ML, Carey L, Brockmeyer DL. The NeuroNavigational 1.2mm Neuroview Neuroendoscope. Neurosurgery 1995;36: 617618.

17. Drake JM, Kestle JR, Milner R, et al. Randomized trial of cerebrospinal fluid shunt valve design in pediatric hydrocephalus. Neurosurgery 1998;43: 294-303.

18. Becker DP, Nulsen FE. Control of hydrocephalus by valveregulated venous shunt: avoidance of complications in prolonged shunt maintenance. J Neurosurgery 1968;28: 215-226.

19. Hoffman HJ, Smith MS. The use of shunting devices for cerebrospinal fluid in Canada. Can J Neurol Sci 1986;13: 81-87.

20. Sainte-Rose C. Shunt obstruction: a preventable complication? Pediatr Neurosurg 1993;19: 156-164.

21. Pang D, Grabb PA. Accurate placement of coronal ventricular catheter using stereotactic coordinate-guided free-hand passage. Technical note. J Neurosurgery 1994;80: 750-755.

22. Steinbok P, Poskitt KJ, Cochrane DD, Kestle JR. Prevention of postshunting ventricular asymmetry by transseptal placement of ventricular catheters. A randomized study. Pediatr Neurosurg 1994;21: 59-64. 